\title{
Evaluation of Visual-Spatial Cognitive Function and Attention in Pilots of Air Force of Islamic Republic of Iran
}

\author{
Almasi Dooghaee. $\mathrm{M}^{1}$ \\ ${ }^{*}$ Ranjbar Naeeni. AR² \\ Khoshdel. $\mathrm{AR}^{3}$ \\ Eslami. $\mathrm{R}^{4}$ \\ Mohsenzadeh. HR5 \\ 1-MD, Neurologist, Neurology \\ Department, Faculty of \\ Medicine, Aja University of \\ Medical Science, Tehran, Iran. \\ 2- ( ${ }^{*}$ Corresponding Author) \\ MD, Neurologist Assitant \\ Professor, Neurology \\ Department, Faculty of \\ Medicine, Aja University of \\ Medical Science, Tehran, Iran. \\ Email: Ranjbar1382@yahoo.com \\ 3- $M D, P h D$, Professor, \\ Epidemiology Research \\ Center, Aja University of \\ Medical Science, Tehran, Iran. \\ 4- MD, Assitant Professor, \\ Faculty of Aerospace and \\ Subaquatic, Aja University of \\ Medical Science, Tehran, Iran. \\ 5- MSC, Instructor, Psychology \\ Department, Aja University of \\ Medical Science, Tehran, Iran.
}

\begin{abstract}
Introduction: The pilot has a continuous flow of various activities that require navigation, attention, and navigation working memory. Fighter pilots are more vulnerable to cognitive impairment due to positive gravitational acceleration. This point indicates the importance of their cognitive assessments.
\end{abstract}

Objective: This study aimed to evaluate visual-spatial cognitive function and attention in the pilots of the Airforce of the Islamic Republic of Iran and compare these factors between fighter pilots and other aviation personnel.

Materials and Methods: An analytic observational cross-sectional study was performed on 49 fighter pilots (group 1) and other aviation personnel (group 2). A list of demographic variables and flight histories was recorded. Then Addenbrooke's Cognitive Examination-Revised, Rey- Osterrieth complex figure test, Forward and Backward Digit Span (FDS and BDS), and Brief Visual-spatial Memory TestRevised were token. Data were analyzed by SPSS $18(\mathrm{P}<0.05)$.

Results: Both groups were homogeneous regarding age, sex, education, militarygrade, flight history, and complaints of cognitive symptoms. The scores of the tests were not statistically significant between the two groups. More than 10 years of flight history and equal or less than 10 years of flight history were respectively related to higher and lower scores in BDS and "recalling words". The scores of FDS were higher in those with equal or less than 400 hours of flight history. The scores of "delayed recalling" were higher in people with more than 400 hours of flight history and those with more than 40 hours of flight history in the last 6 months.

Discussion and Conclusion: There was no difference in visual-spatial function and attention between fighter pilots and other aviation personnel, but flight history was related to the scores of some cognitive subtests.

Keywords: Attention, Cognition, Pilots. 


\section{بررسى عملكرد شناختى بينايى - فضايى و توجه در خلبانان ارتش جمهورى اسلامى ايران}

مصطفى الماسى دوغائى'، "عليرضا رنجبر نائينى ‘، عليرضا خوشدل"، رضا اسلامى"، حميدرضا محسنزادهه

جكيده

مقدمه: كار خلبان جريان مستمرى از فعاليتهايى است كه مستلزم جهت يابى، توجه و حافظه كارى ناوبرى كارا است. خلبانان جنكَنده به علت تحمل شتاب كرانشى بيشتر، در معرض اختلالات شناختى هستند و انجام ارزيابىهاى شناختى در آنها اهميت بسزايى دارد. هدف: هدف از يزوهش حاضر ارزيابى عملكرد شناختى بينايى-فضايى و توجه خلبانان ارتش جمهورىى اسلامى ايران و

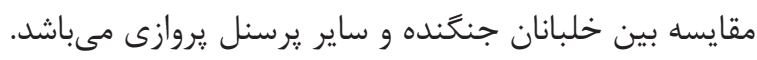

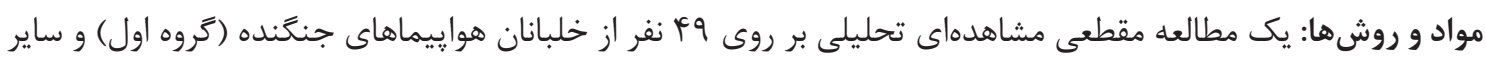

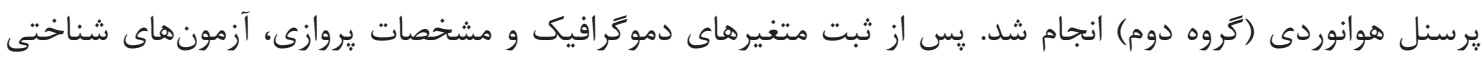

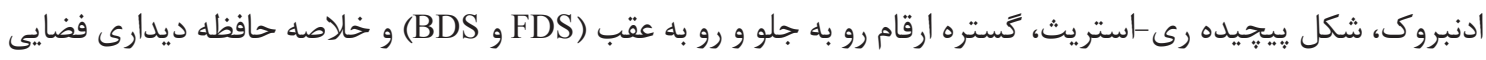

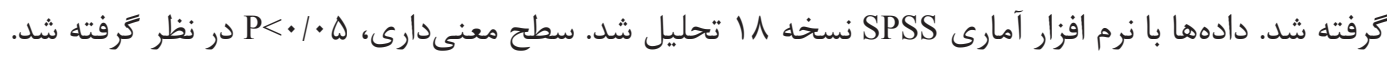

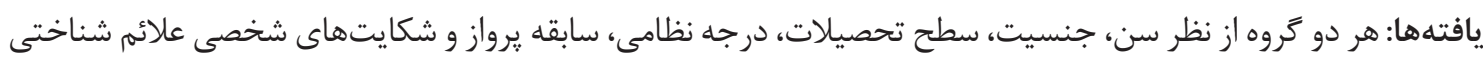

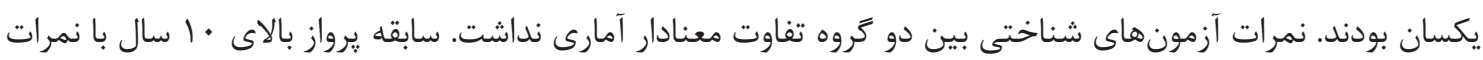

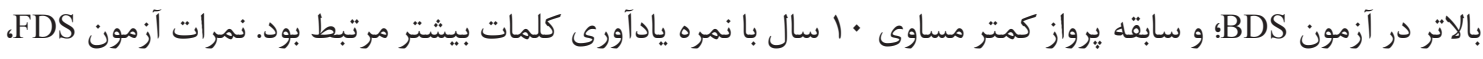

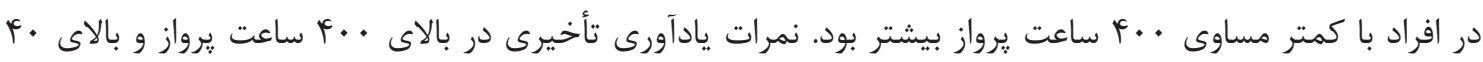
ساعت يرواز در 9 ماه كذشته، بيشتر بود. بحث و نتيجه مَيرى: عملكرد بينايى فضايى و توجه در بين خلبانان هواييماهاى جنكخنده و ساير برسنل هوانوردى تفاوت

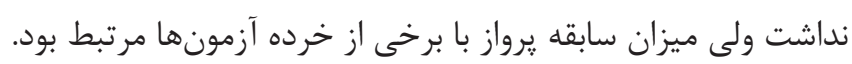

كلمات كليدى: توجه، خلبان، عملكرد شناختى.

مجله علوم مر اقبتى نظامى || سال ششم | شماره ع | زمستان

غرب، بهره بردن از نيروى هوايى كار آمد، غير قابل كتمان است ( ).

مقلمهـ

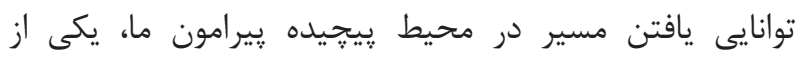

در سند جشم انداز افق F • F ا كه توسط مقام معظم رهبرى ابلاغ اساسىترين عملكردهاى شناختى است. جهتيابى فضايى روندى لئى

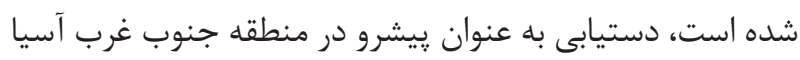

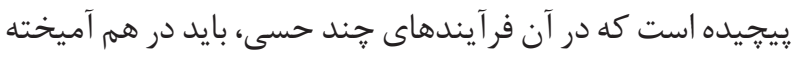

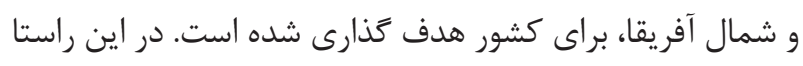
شوند و با تغيير زمان و مكان شخص، نيز خود را تطبيق دهند (r). و براى داشتن قدرت دفاعى بازدارنده در برابر قدرتهاى شرق و و 
نيروهاى مسلح، به ويزه خلبانان، بيشتر ترديد و امروزه در اغلب

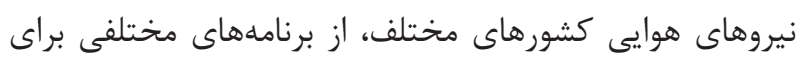

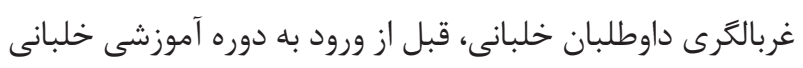

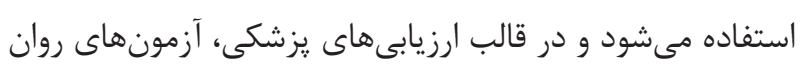

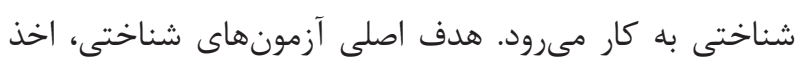

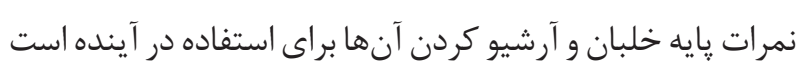

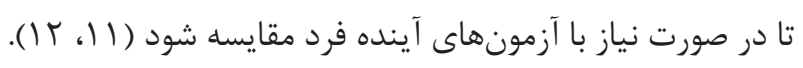

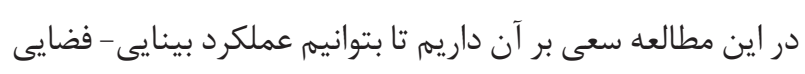

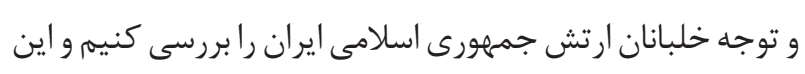

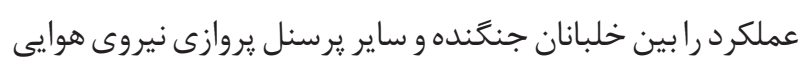
ارتش مقايسه كنيم. بر اساس منابع در دسترس، تاكنون جنين

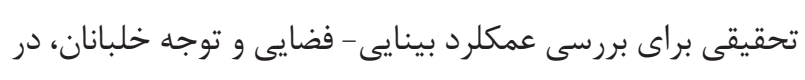
منابع علمى موجود كشور ما، وجود ندارد. مطالعات محدودى دري در بردي

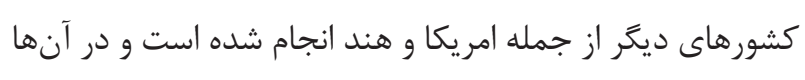
جنبه بسيار محدودى از عمكلرد بينايى - فضايى و توجه، بررسى دئ

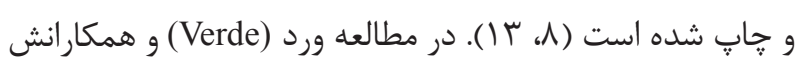
تفاوتهاى جنسيتى در حافظه ناوبرى خلبانان و غير خلبانان

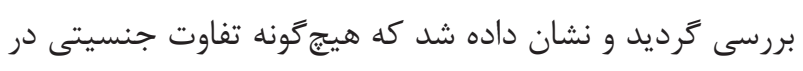

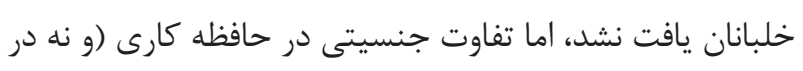
ياد كيرى و يادآورى تأخيرى) در جمعيت عمومى يافت شد (1).

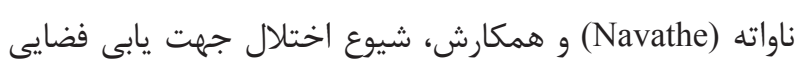

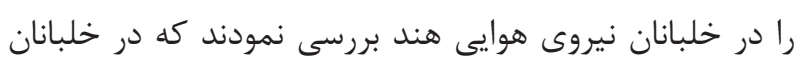

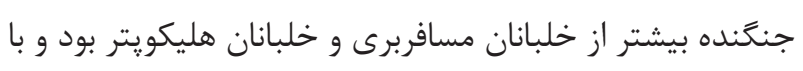

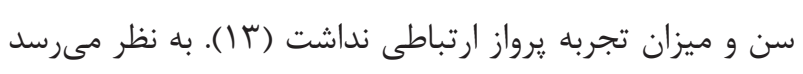

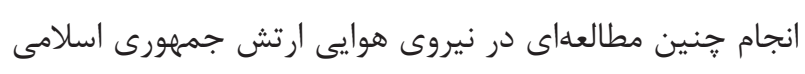

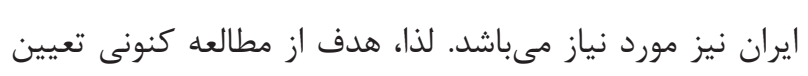

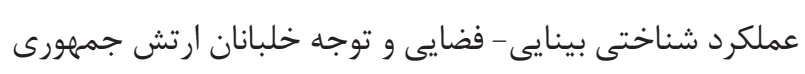

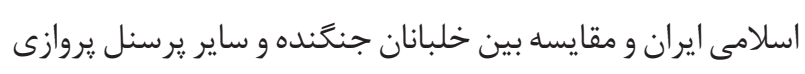

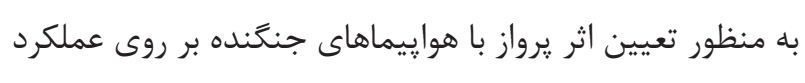

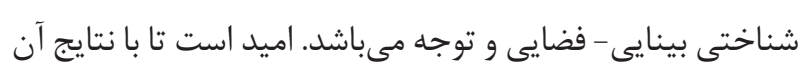
بتوانيم قدمى را براى بهبود وضعيت خلبانان برداريم.

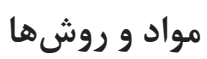

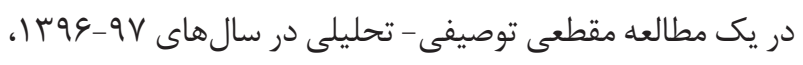

جهتيابى نياز به جهار مرحله از يردازش اطلاعات دارد كه شامل دريافت حسى (Sensory Input)، درك و شناخت /Perception) (Execution و و اجراى يك رفتار (Selection) انتخاب (Sognition) مياشد و نيازمند ملزومات شناختى و فيزيكى of an Action) است. در حين يرواز خلبان از همه اين مراحل استفاده مى كنند

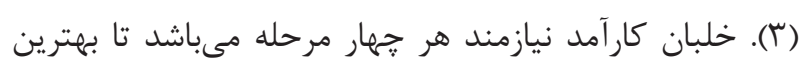

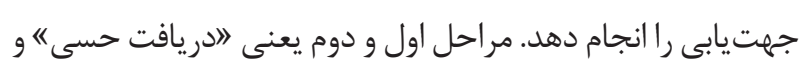

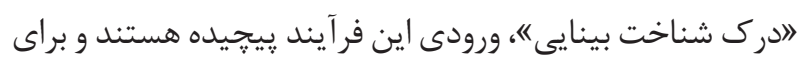
داشتن يك خروجى مطمئن، بايد اطلاعات به درستى وارد سيستم

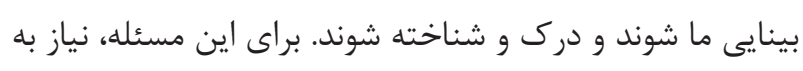

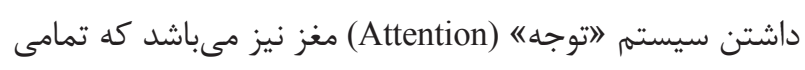

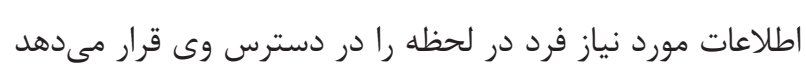

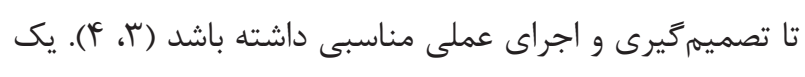

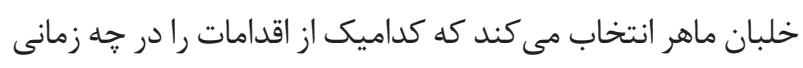

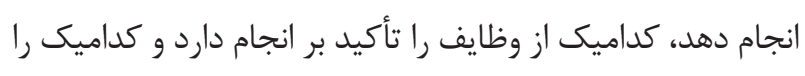

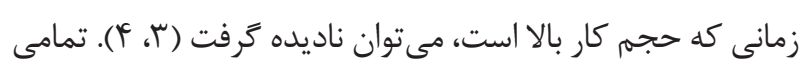
اين موارد جز تكاليف حافظه كارى ناوبرى هستند (ه).

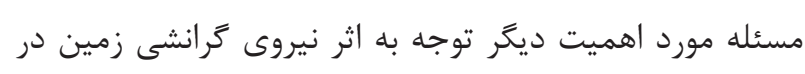

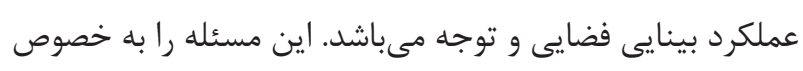

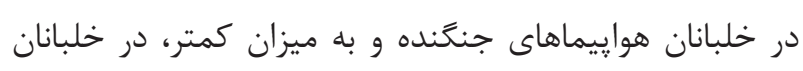

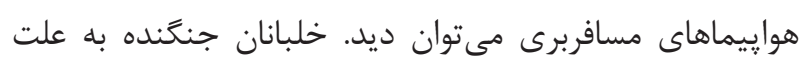

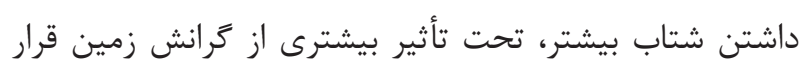

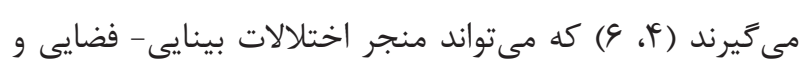
توجه بيشترى شود.

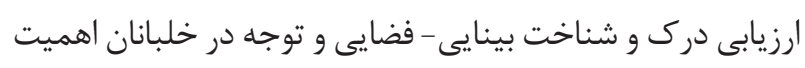
بسزايى دارد. به طور كلى خلبانان نسبت به غير خلبانان توانايى

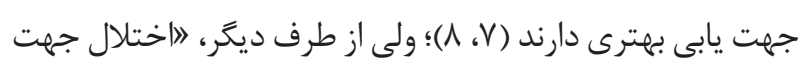
يابى فضايى" براى يروسه مهمم خلبانى، مىتواند بِيامدهاى غيرقابل

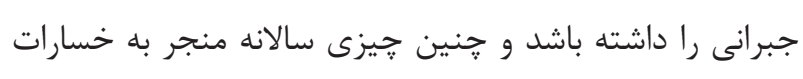

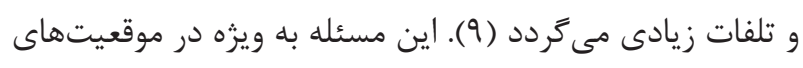

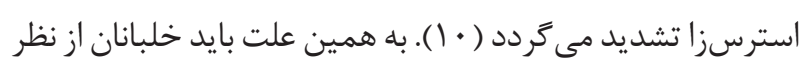

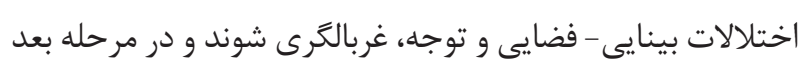

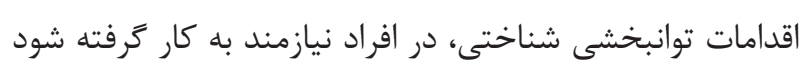

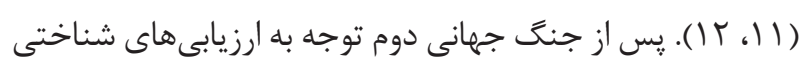


وى جمع آورى شد و بعد از كدَذارى وارد برنامه آمارى SPSS

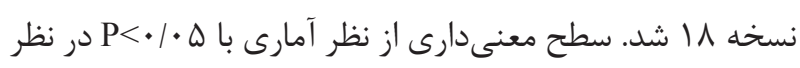
كرفته شد.

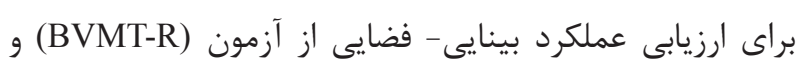

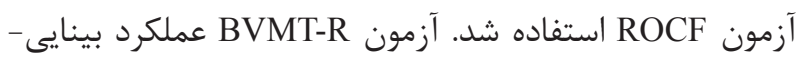

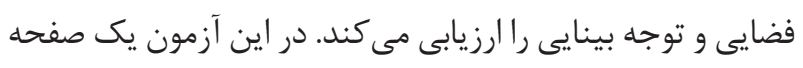

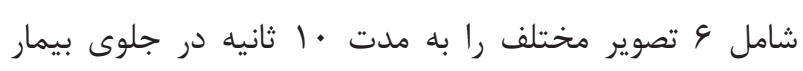

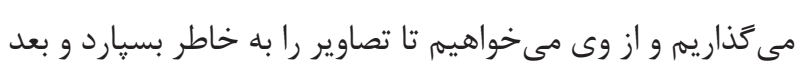

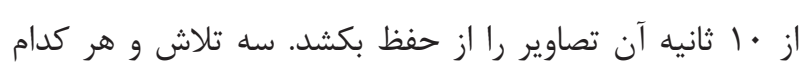

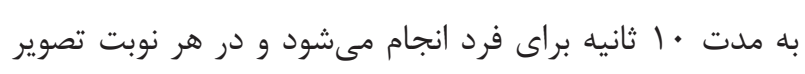

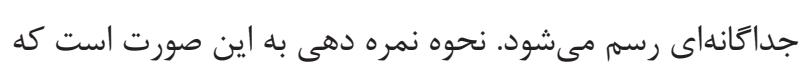

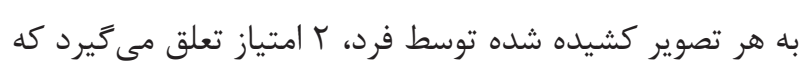
ا نمره براى كشيدن صحيح تصوير و ا نمره براى محل صحيح

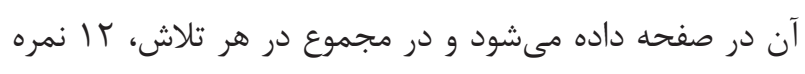

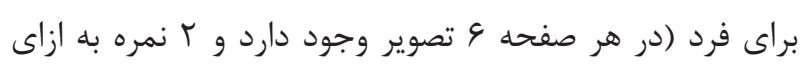

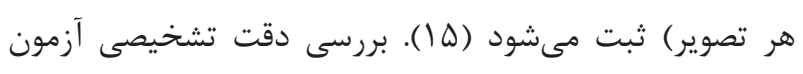

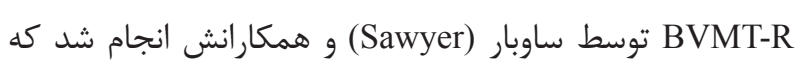

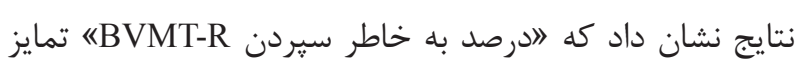

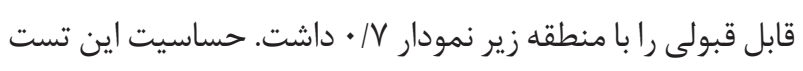

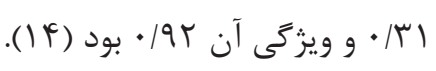

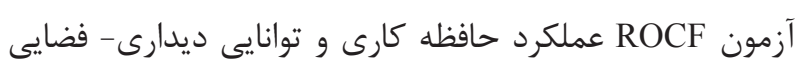
را بررسى مى كند. اين آزمون از يك تصوير يِيجيده تشكيل شده

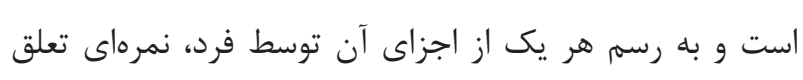

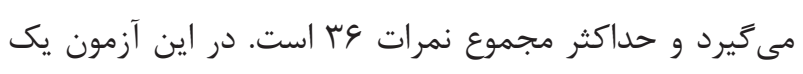

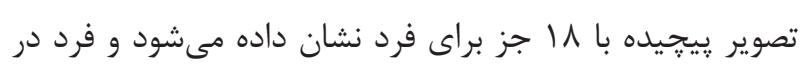

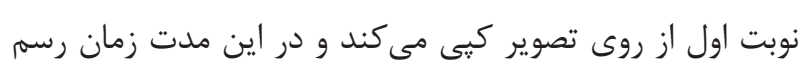

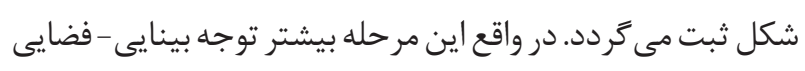
(Visuospatial Attention)

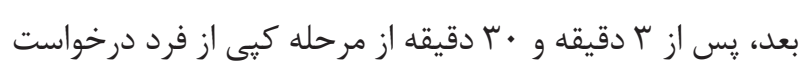

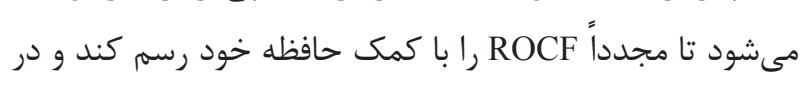

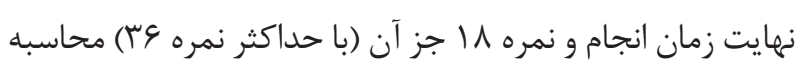

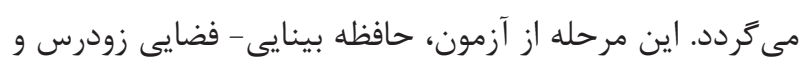

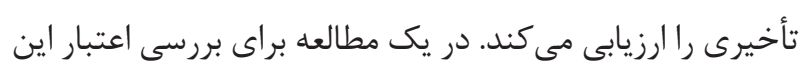

به روش سرشمارى، كليه يرسنل نيروى هوايى ارتش جمهورى

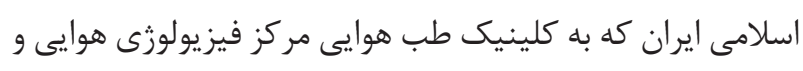

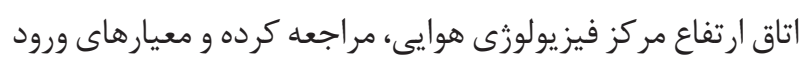

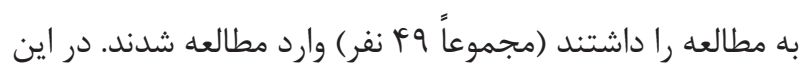
مطالعه عملكرد شناختى بينايى - فضايى و عملكرد شناختى - توجه

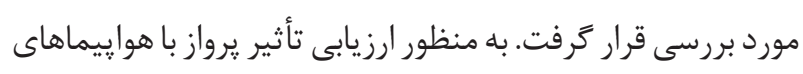

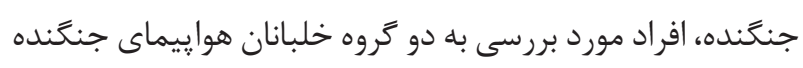

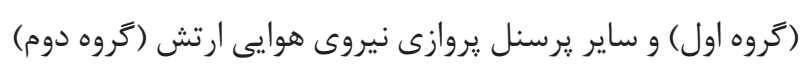

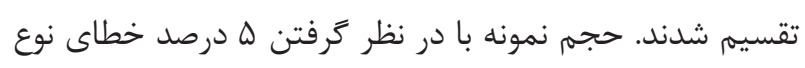

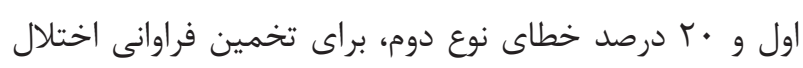

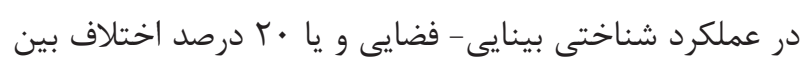

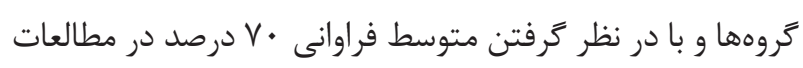

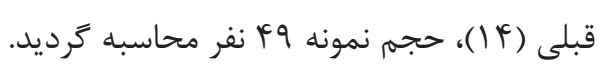

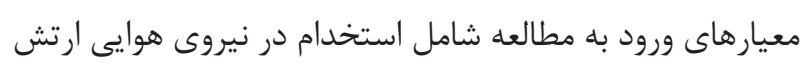
جمهورى اسلامى ايران به عنوان يرسنل يروازى، عدم داشتن

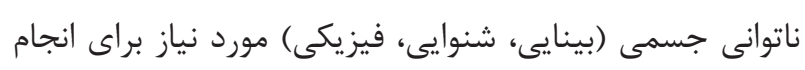

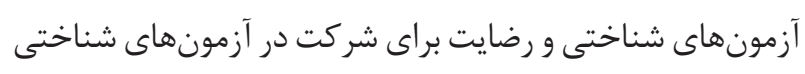

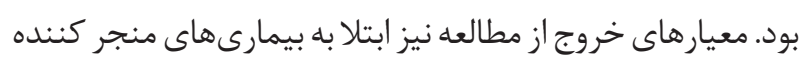

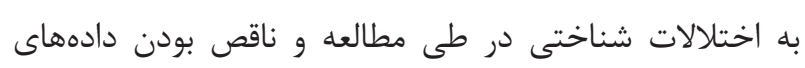
دريافتى بود. براى تمامى افرادى كه براى انجام معاينات يزشكى دورهاى خون خود و آموزش هاى دورهاى هييوكسى حين برواز مراجعه كرده بودند،

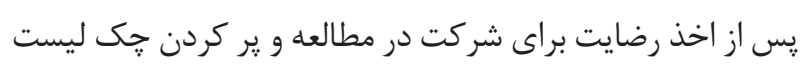

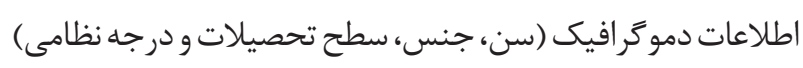

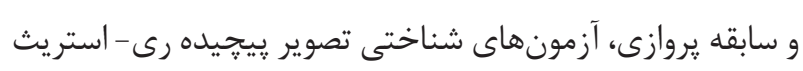
(Rey-Osterrieth Complex Figure Test (ROCF)) (Addenbrooke's Cognitive شناختى ادنبروك بازبينىشده (ACE-R)) Examination -Revised (ACE-R)) ديدارى فضايى بازبينىشده Brief Visuospatial Memory Test - Revised (BVMT-R)) جلو و رو به عقب (Forward Digit Span (FDS) و و (BDSward) انجام شد. اين آزمون ها توسط متخصص مغز و اعصاب مجرب در زمينه اختلالات شناختى كرفته شد. تمامى

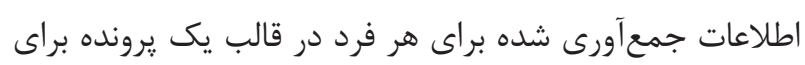




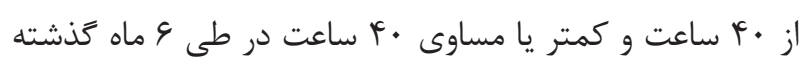

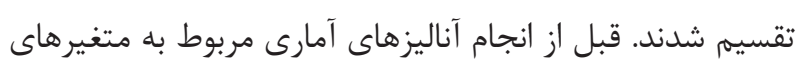

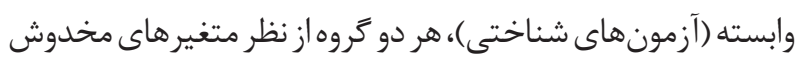
كننده مثل سن، جنس، سطح تحصيلات، درجه نظامى، سابقه

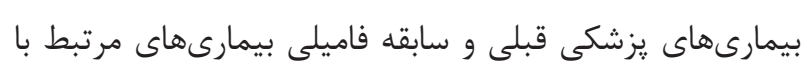

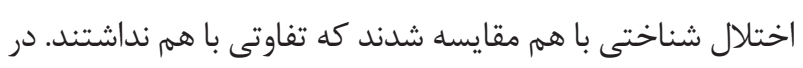

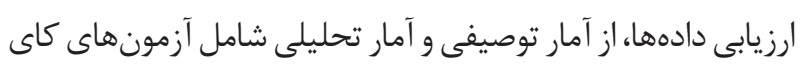

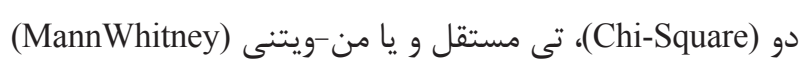

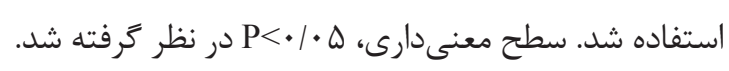

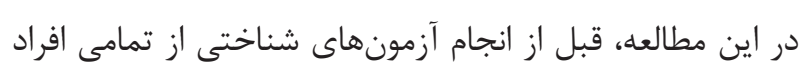

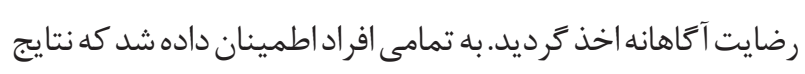

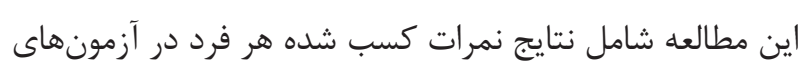
شناختى، فقط در دسترس يزوهشكَران مىباشد و فقط براى امور

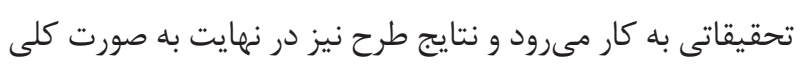
انتشار مىيابد. اصول كميته اخلاق نشر (COPE) رعايت گرديد.

\section{يافتهها}

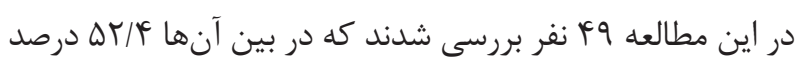

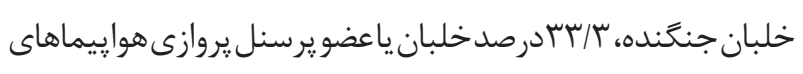

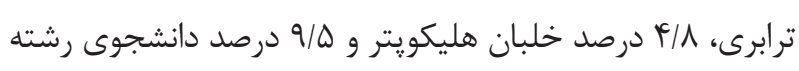

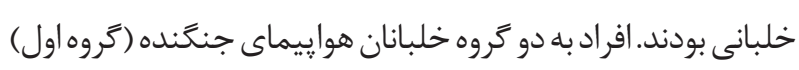
و غير خلبانان هوإيماى جنَخنده (كروه دوم) تقسيم شدند. ميانگين

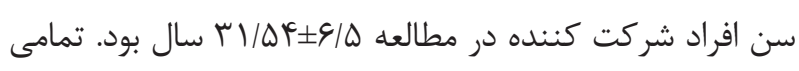

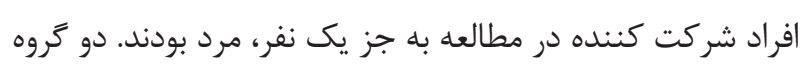

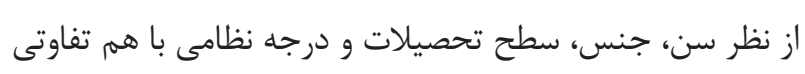

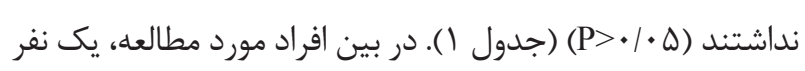

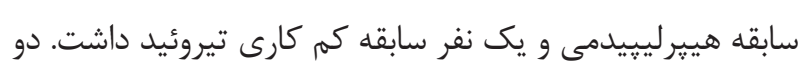

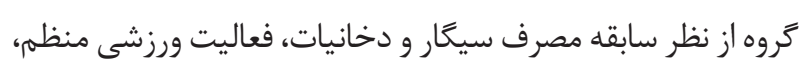
سابقه فاميلى بيمارىهاى مرتبط با اختلال شناختى و مدت زمان

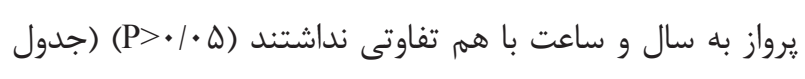

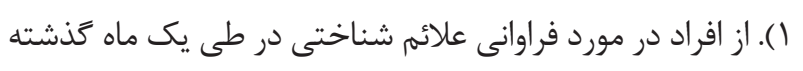

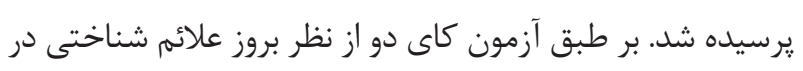

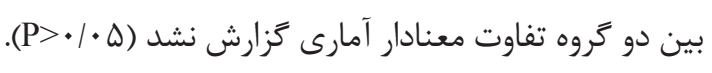

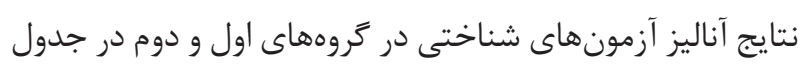

• 9 درصد (بين اج درصد تا 99 درصد) و كمترين نمره همبستكى

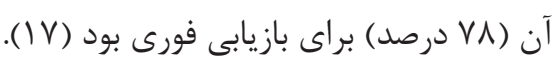

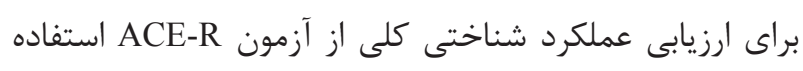

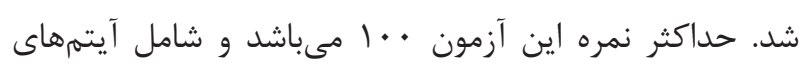

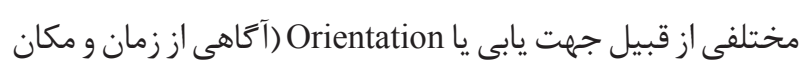
كنونى)، رجيستر يا Registration (توانايى ثبت اطبل العاعات)، توجه

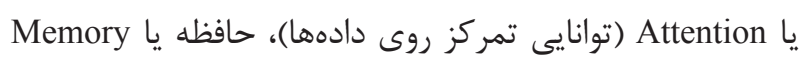

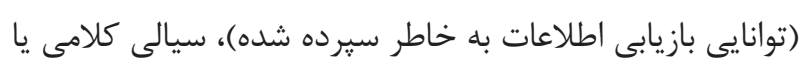

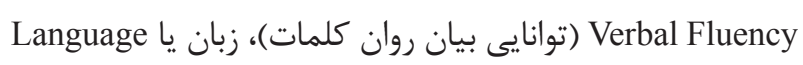

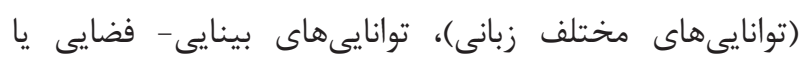

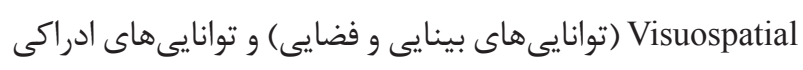

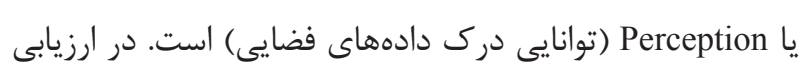

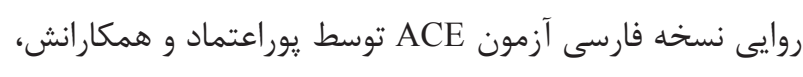

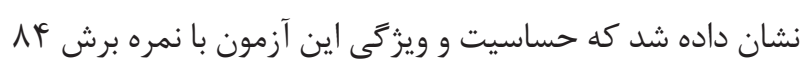

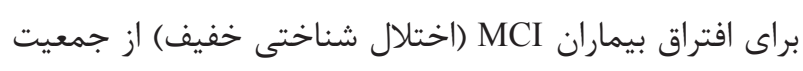
نرمال، به ترتيب سو درصد و الو درصد مى باشد (1) (1).

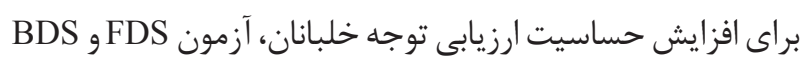

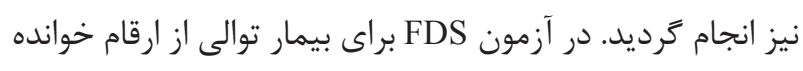

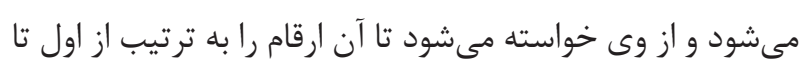

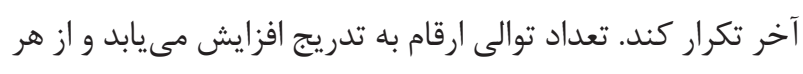
تعداد توالى ارقام، دو توالى براى فرد خوانده مىشود. دئ در آزمون BDS

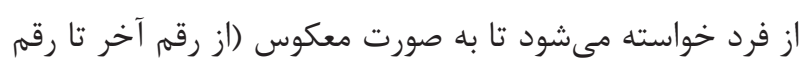

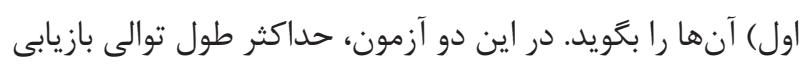

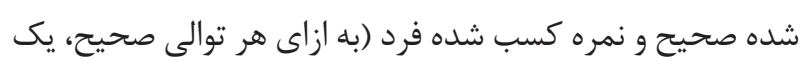

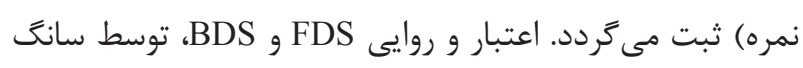

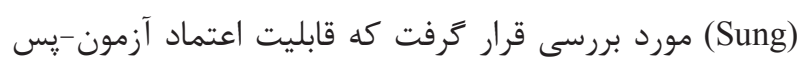

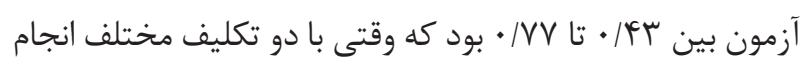

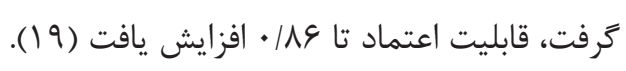

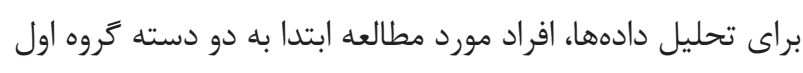
(شامل خلبانان هوإيماهاى جنَّنده) و كروه دوم (ساير يرسنل

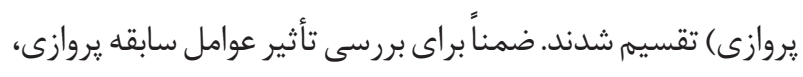

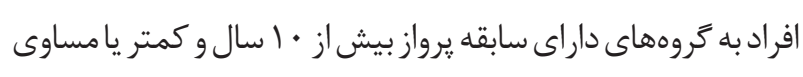

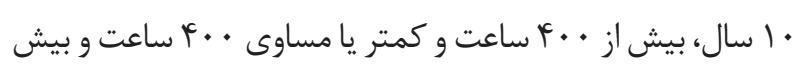


جدول ا - مقايسه مشخصات دموكر افيكى و مشخصات يروازى در دو كروه مورد مطالعه

\begin{tabular}{|c|c|c|c|}
\hline سطح معنى دارى & حروه دوم (ساير يرسنل يروازى) & 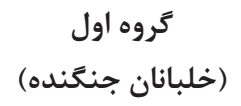 & متغير \\
\hline${ }^{\dagger} \cdot 19 \mathrm{~m} \Delta$ & $r \mid / F \pm \varepsilon / \Lambda$ & $r 1 / 9 \pm 9 / 4$ & سن \\
\hline$* \cdot \cdot \Delta F$ & $\% 1 \cdot 1 \cdot$ & $\%$ HI/ & داشتن سطح تحصيلات فوق ليسانس و بالاتر \\
\hline$* \cdot r \cdot r$ & $\% \mid \Delta / \cdot$ & $\% 4 \cdot 19$ & داشتن درجه سرگردى و بالاتر \\
\hline */ • & $\% / . / \cdot$ & $\% \% / \Delta$ & داشتن سابقه بيمارى قبلى يزشكى \\
\hline$* / F F F$ & $\% /$ & $\% 1 \pi / 9$ & داشتن سابقه مصرف سيعار و دخانيات \\
\hline$* / r 94$ & $\% .9 \Delta / \cdot$ & $\% V V / r$ & داشتن فعاليت ورزشى منظم \\
\hline$\dagger^{\dagger} \cdot 1994$ & $9 / \vee \Delta \pm 1 / \vee$ & $1 \cdot 194 \pm 1 / 4$ & تعداد كل سالهاى يرواز \\
\hline${ }^{\dagger} \cdot 10 \vee 9$ & 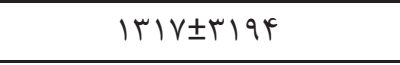 & $1 \cdot 9 \wedge \pm f \cdots$ & تعداد كل ساعتهاى يرواز \\
\hline$+\cdot / \cdot V \mathrm{~V}$ & $\% \cdot r \cdot 1 \cdot$ & $\% .4 \cdot 19$ & درصد يروازهاى در طول در روز \\
\hline$\dagger \cdot / \mathbb{\uparrow} \Delta \Delta$ & $1 \Delta \Delta \pm \Delta r$ & $r r \pm V \wedge$ & مدت زمان يرواز در 9 ماه كذشته (ساعت) \\
\hline
\end{tabular}

جدول r- مقايسه ميانكَين نمرات آزمونهاى شناختى در دو تروه خلبانان جنَّنده و ساير يرسنل يروازى

\begin{tabular}{|c|c|c|c|c|c|}
\hline سطح معنى دارى & حداكثر نمره & ميانغين土|نحراف معيار & ميانغين土|نحراف معيار & ميانغين土|نحراف معيار & ن آزمون \\
\hline & & & & & زمون ROCF (كيى كردن) \\
\hline$\because / A T \Delta$ & re & $r \Delta / \Delta \pm 1 / r$ & $r \Delta / r \pm 1 / \varphi$ & $q r \Delta \pm \cdot / \Lambda$ & نمره كل كسب شده \\
\hline \multirow[t]{2}{*}{$\dot{\dagger} \cdot / 4 t \cdot$} & - & $\mid f V \pm \Delta \Delta$ & $\mid \Delta V \pm \varphi \wedge$ & $\mid F V \pm \Delta \Delta$ & مدت زمان رسم شكل \\
\hline & & & & \multicolumn{2}{|c|}{ زمون ROCF (r دقيقه بعد از كيى) } \\
\hline$* / T T$. & re & $r \mu / r \pm g / r$ & $F T / T \pm G / \Lambda$ & $r r / \Delta \pm r / \Delta$ & نمره كل كسب شده \\
\hline \multirow[t]{2}{*}{$+\cdot / \mathcal{F} \Delta \varphi$} & - & $11 \wedge \pm f$. & $\mid r T \pm F \Delta$ & $\| r \pm r \Delta$ & مدت زمان رسم شكل \\
\hline & & & & \multicolumn{2}{|c|}{ آزمون ROCF ( • ب دقيقه بعد از كيى) } \\
\hline$* /$ MFT & re & $r r / F \pm \varepsilon / D$ & $r Y / I \pm G / 9$ & $r / / 9 \pm r / 9$ & نمره كل كسب شده \\
\hline \multirow[t]{2}{*}{$\dagger \cdot 109 V$} & - & $V \Delta \pm r r$ & $V V \pm r r$ & $V r \pm r g$ & مدت زمان رسم شكل \\
\hline & & & & & زمون FDS \\
\hline$\dagger \cdot 19 \mu \mathrm{G}$ & 19 & $9 / \cdot \pm 1 / 9$ & $\Lambda / \Lambda \pm Y / \cdot$ & $9 / 1 \pm 1 / 9$ & نمره كل كسب شده \\
\hline \multirow[t]{2}{*}{$+\cdot 19 \wedge \Delta$} & $\Lambda$ & $9 / 1 \pm 1 / r$ & $9 / 1 \pm 1 / 9$ & $9 / 1 \pm 1 / r$ & حداكثر طول توالى \\
\hline & & & & & زمون BDS \\
\hline$\dagger \cdot 1911$ & 19 & $q / T \pm 1 / r$ & $\varphi / r \pm 1 / 0$ & $9 / \Gamma \pm 1 / \cdot$ & نمره كل كسب شده \\
\hline \multirow[t]{2}{*}{$+\cdot|\Lambda| r$} & $\Lambda$ & $F / \Delta \pm \cdot / V$ & $p / 9 \pm \cdot / 9$ & $\varphi / 0 \pm \cdot / 9$ & حداكثر طول توالى \\
\hline & & & & & زمون BVMT-R \\
\hline$\dagger \cdot /$ FF. & ir & $V / \Lambda \pm r / r$ & V/r土m/l & $9 / V \pm 1 / \Delta$ & نمره كل (تلاش اول) \\
\hline$\dagger \cdot 19 r \wedge$ & ir & $1 \cdot / \Lambda \pm 1 / 9$ & $1 \cdot \mid \Lambda \pm 1 / \pi$ & $1 \cdot / V \pm 1 / \Lambda$ & نمره كل (تلاش دوم) \\
\hline \multirow[t]{2}{*}{$\dagger \cdot \mid 94 T$} & ir & $11 / 1 \pm \cdot 19$ & $11 / \Lambda \pm \cdot 19$ & $11 / V \pm \cdot / V$ & نمره كل (تلاش سوم) \\
\hline & & & & & زمون ACE-R \\
\hline$* / r \mid r$ & $1 \cdots$ & $q \leftrightarrow / q \pm r / r$ & $q \varphi / F \pm r / V$ & $q r / \varphi \pm r / 9$ & نمره كل آزمون \\
\hline
\end{tabular}


در آناليز آزمونهاى شناختى بر اساس تعداد ساعتهاى يرواز در

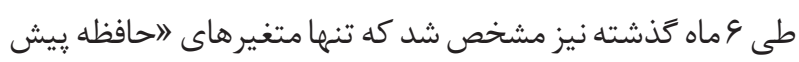

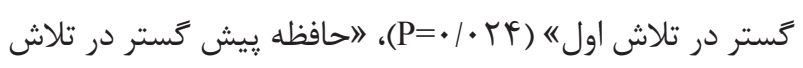

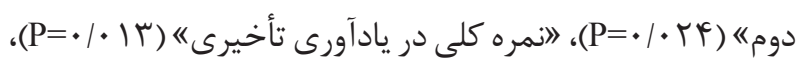

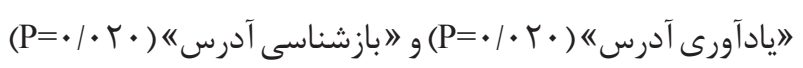

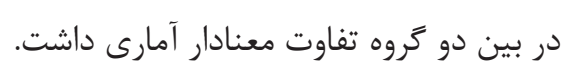

\section{بحث و نتيجهَيرى}

مطالعه حاضر با هدف بررسى عملكرد شناختى بينايى - فضايى نيى

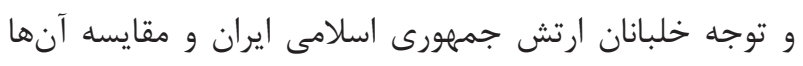

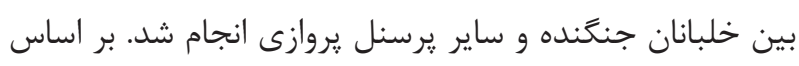

شماره r آمده است. بر اين اساس ميانخين نمرات تمامى آزمونهاى

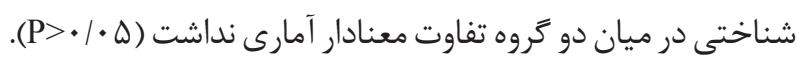

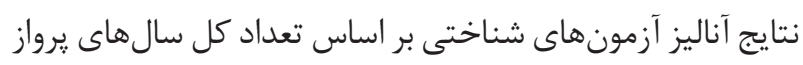

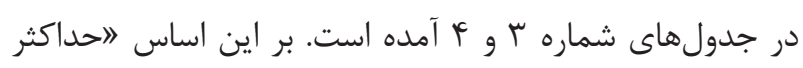

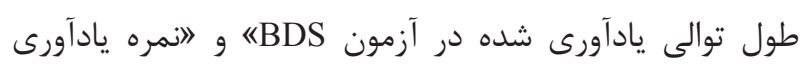

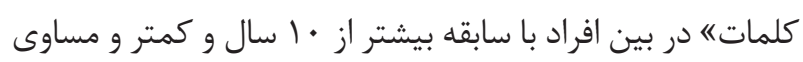

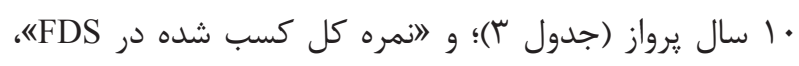

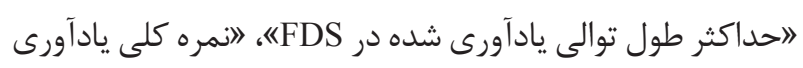

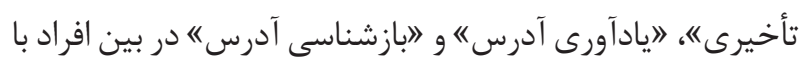

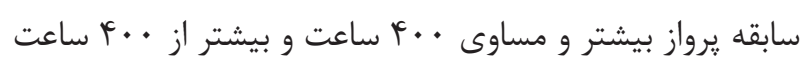

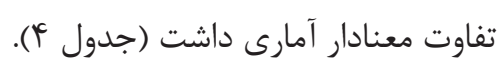

جدول بـ - مقايسه ميانَين و انحر اف معيار نمرات آزمونهاى شناختى به تفكيك تعداد كل سال هاى يرواز

\begin{tabular}{|c|c|c|c|c|c|}
\hline سطح معنىدارى & حداكثر نمره & ميانگين土 انحراف معيار & ميانغين土 انحراف معيار & 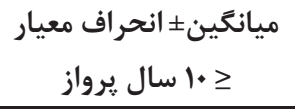 & ن آزمون \\
\hline & & & & & آزمون ROCF (كيى كرنن) \\
\hline$* / / V \cdot 9$ & G & $r \Delta / \Delta \pm 1 / r$ & $\Gamma \Delta / \varepsilon \pm \cdot / \Lambda$ & $r \Delta / \Delta \pm 1 / \varphi$ & نمره كل كسب شده \\
\hline \multirow[t]{2}{*}{$\dagger \cdot / \cdot \Delta \cdot$} & - & $\mid f V \pm \Delta \Delta$ & $\| r \cdot \pm r \wedge$ & $19 r \pm 09$ & مدت زمان رسم شكل \\
\hline & & & & \multicolumn{2}{|c|}{ آزمون ROCF (ז دقيقه بعد از كيى) } \\
\hline$* \cdot 1 \cdot 9$ & re & $r / r \pm \varepsilon / T$ & $r \varphi / q \pm \varepsilon / r$ & $r \mid / T \pm g / r$ & نمره كل كسب شده \\
\hline \multirow[t]{2}{*}{ †./KTI } & - & $\| \wedge \pm r$. & I. $9 \pm$ ג & $1 r \Delta \pm r$. & مدت زمان رسم شكل \\
\hline & & & & \multicolumn{2}{|c|}{ زازمون ROCF (• • دقيقه بعد از كيى) } \\
\hline$* / 1 \mathrm{FV}$ & re & $r r / F \pm g / D$ & $T Y / \varepsilon \pm G / T$ & $r / / 9 \pm \varepsilon / \Lambda$ & نمره كل كسب شده \\
\hline \multirow[t]{2}{*}{$\dagger \cdot|q \mu|$} & - & VDEYr & $V Y \pm Y$. & $V \varepsilon \pm r \Delta$ & مدت زمان رسم شكل \\
\hline & & & & & آزمون FDS \\
\hline$\dagger \cdot / \Lambda \vee f$ & 19 & $9 / \cdot \pm 1 / 9$ & $9 / 1 \pm 1 / 9$ & $q / 1 \pm r / \cdot$ & نمره كل كسب شده \\
\hline \multirow[t]{2}{*}{$+\cdot|94|$} & $\Lambda$ & $9 / 1 \pm 1 / r$ & $9 / 1 \pm 1 / r$ & $9 / 1 \pm 1 / r$ & حداكثر طول توالى \\
\hline & & & & & آزمون BDS \\
\hline$\dagger \cdot 11 \mathrm{r \Delta}$ & 19 & $\varepsilon / \Gamma \pm 1 / r$ & $4 / \wedge \pm 1 / \Delta$ & $\Delta / 9 \pm 1 / 1$ & نمره كل كسب شده \\
\hline \multirow[t]{2}{*}{$\dagger \cdot / \cdot r \Lambda$} & $\Lambda$ & $r / \Delta \pm \cdot / V$ & $r / 9 \pm \cdot / \Lambda$ & $\varphi / \mu \pm \cdot / \varphi$ & حداكثر طول توالى \\
\hline & & & & & آزمون BVMT-R \\
\hline$\dagger \cdot / F \xi$. & ir & $V / I \pm r / r$ & $V / r \pm T / l$ & $G / V \pm 1 / \Delta$ & نمره كل (تلاش اول) \\
\hline$\dagger \cdot 194 \wedge$ & Ir & $1 \cdot / \Lambda \pm 1 / 9$ & $1 \cdot \mid \Lambda \pm 1 / r$ & $1 \cdot / 1 \mathrm{~V} / \mathrm{A}$ & نمره كل (تلاش دوم) \\
\hline \multirow[t]{2}{*}{$\dagger \cdot \mid 9 F T$} & IT & $11 / \wedge \pm \cdot / 9$ & $11 / \wedge \pm \cdot / 9$ & $11 / \mathrm{V} \pm \cdot / \mathrm{V}$ & نمره كل (تلاش سوم) \\
\hline & & & & & آزمون ACE-R \\
\hline$* / 4 r q$ & $1 \cdots$ & $q r / \varphi \pm r / q$ & $q Y / q \pm r / 4$ & $q \mu / 4 \pm r / q$ & نمره كل آزمون \\
\hline$\dagger \cdot / \cdot \varphi$. & r & $r / q \pm \cdot / r$ & $r / \Lambda \pm \cdot / 9$ & 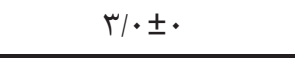 & يادآورى كلمات \\
\hline
\end{tabular}


جدول F - مقايسه ميانكَين نمرات آزمونهاى شناختى به تفكيك تعداد كل ساعتهاى برواز

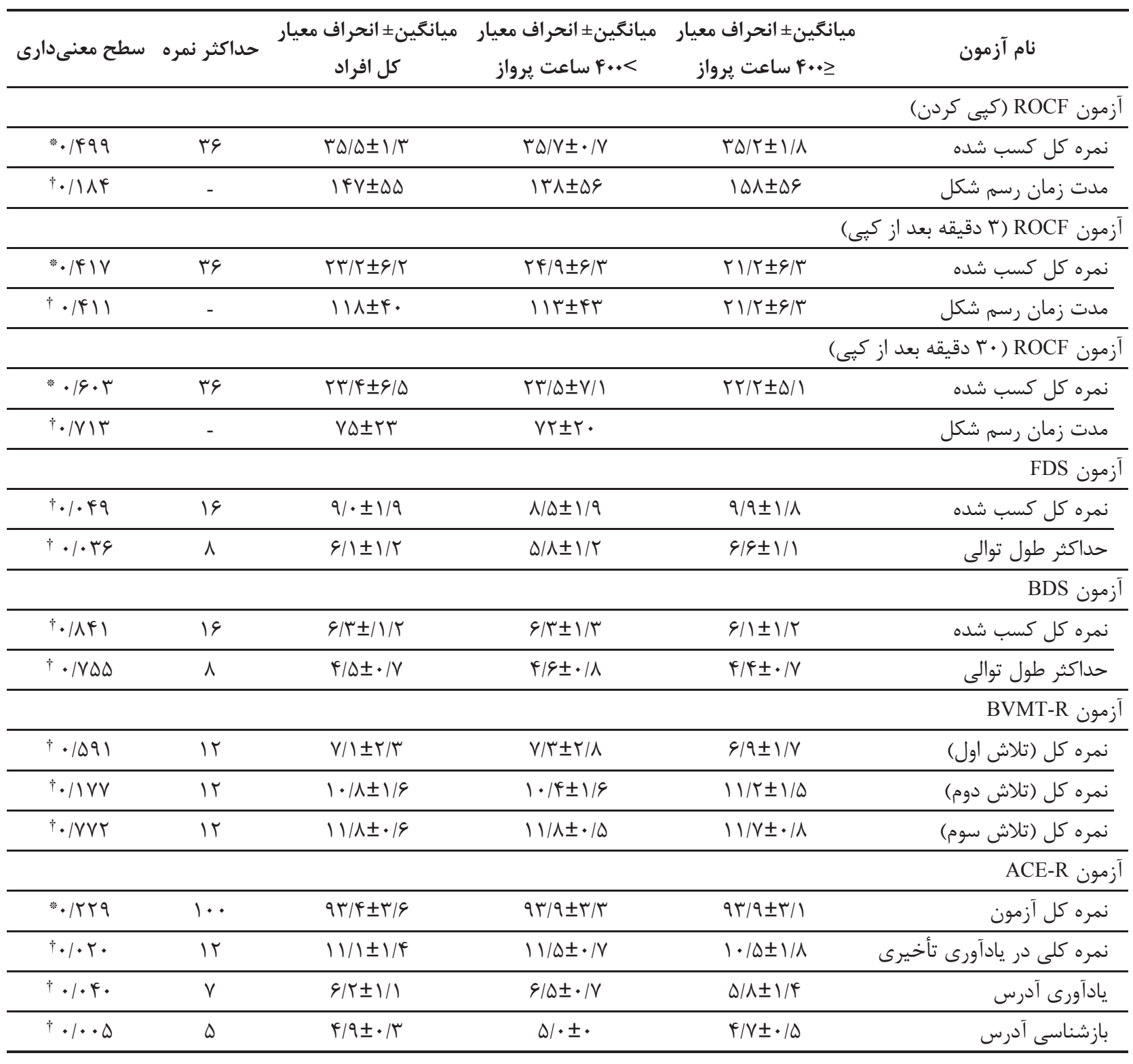

كه مربوط به يادآورى تأخيرى (شامل نمره كلى يادآورى تأخيرى،

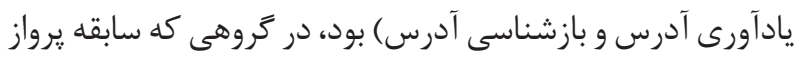

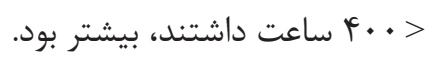

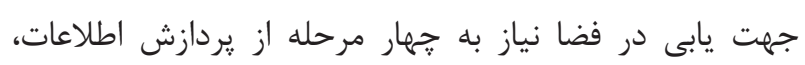

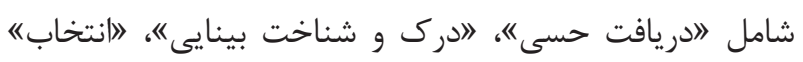

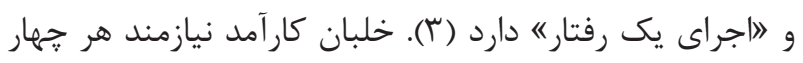

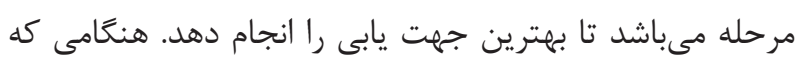

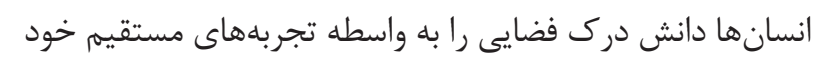

نتايج اين مطالعه، در دو كروه خلبانان هوإيماى جنگَنده و ساير

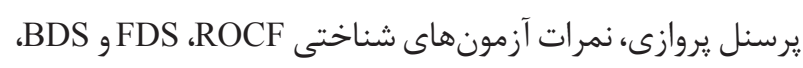

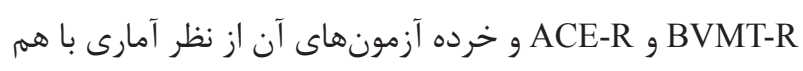
يكسان بود. از طرف ديكر، صرف نظر از نوع وسيله يروازى، داشتن سابقه يرواز > • ا سال، با يادآورى طول توالى بيشترى در در آزمون

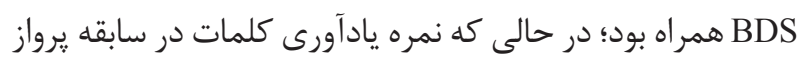

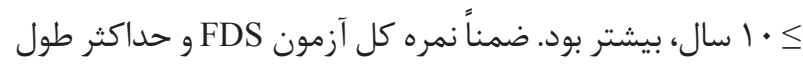

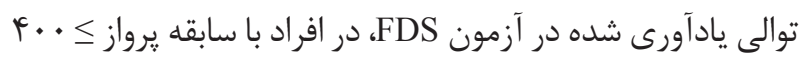

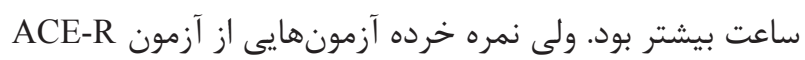


يروازى داشته باشند (4)، ؟). نتايج به دست آمده از اين مطالعه،

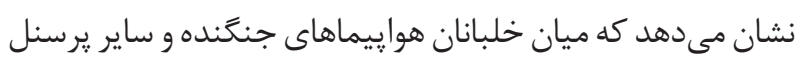

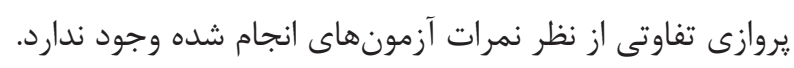

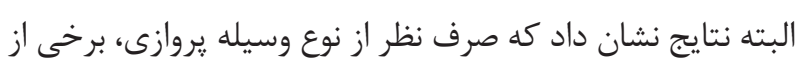

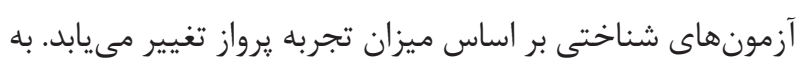

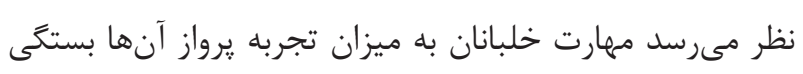

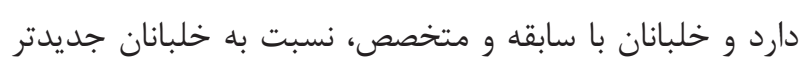

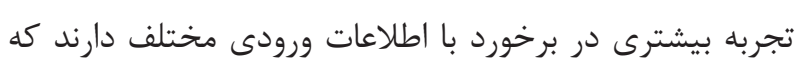

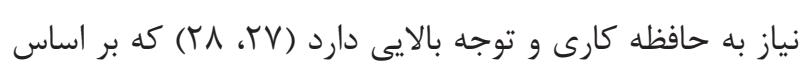

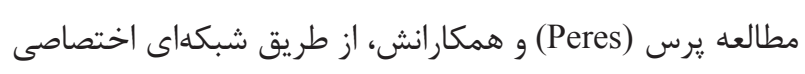

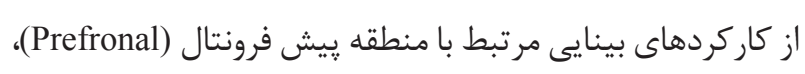

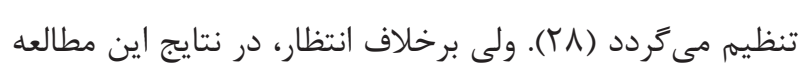

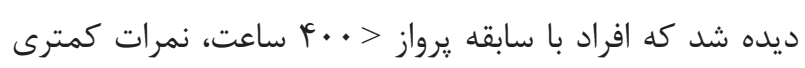

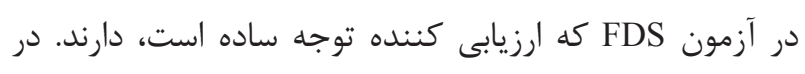

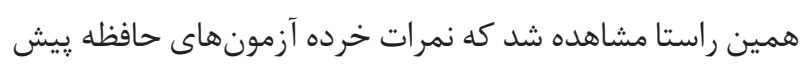

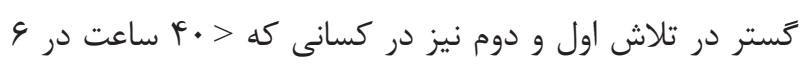

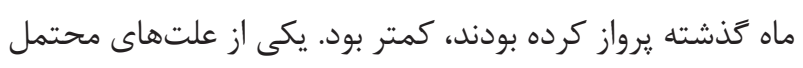

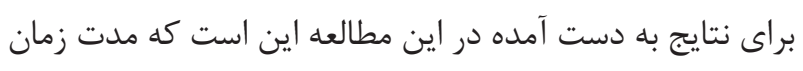

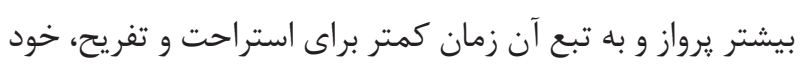

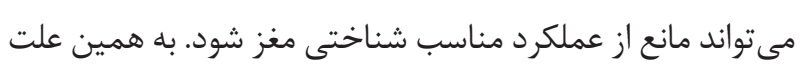
توصيه مى كردد محدوديتهايى براى ميزان ساعات يرواز خلبانان و يرسنل بروازى در نظر ترفته شود.

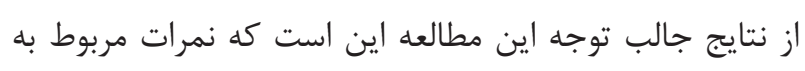

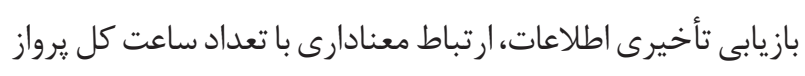

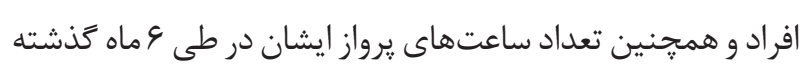

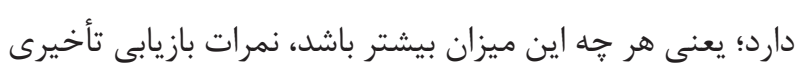

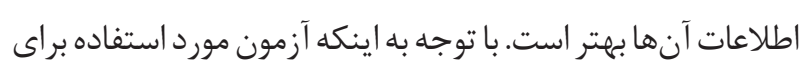

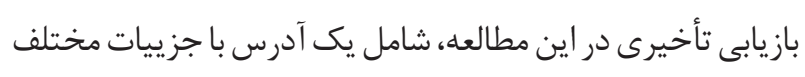

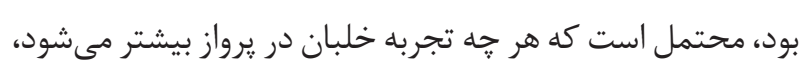
تأكيد بيشترى بر جزييات آدرسها مى كند و به به همين علت نمرات بالاترى را كسب مىنمود. البته با توجه به اينكه مطالعات انجام شده و منتشر شده در زمينه ارزيابىهاى شناختى خلبانان

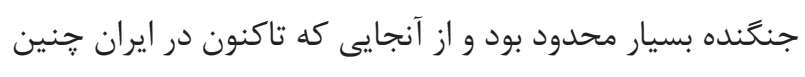
مطالعهاى انجام نشده است، امكان مقايسه يافتهها به طور كامل
تفاوتهاى فردى بارزى را نشان مىدهند. به نظر مىرسد كه اين

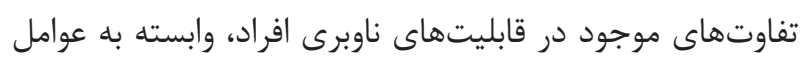

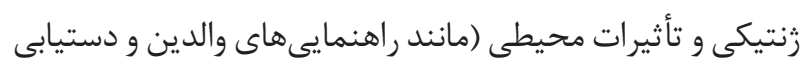

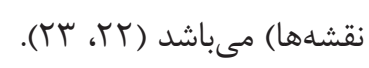

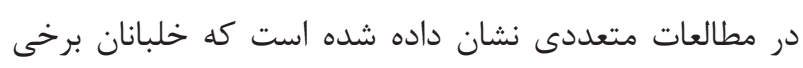

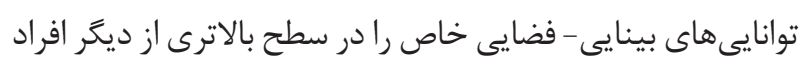

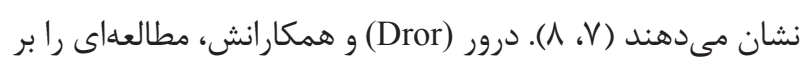
روى 19 خلبان و 1 ا فرد شاهد انجام دادند و دريافتند كه خلبانان

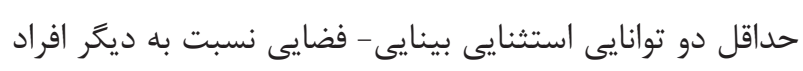

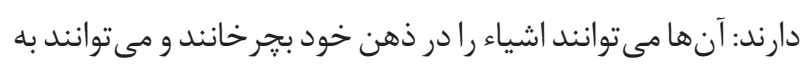

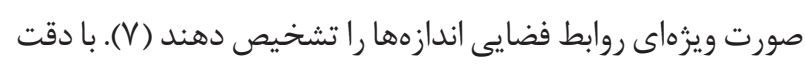
در نتايج اين مطالعه هم مشاهده مىشود كه به طور كلى نمراتئ نمرات

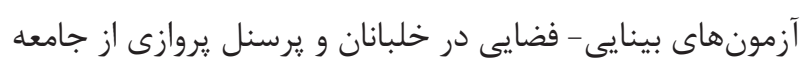

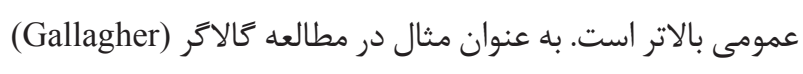

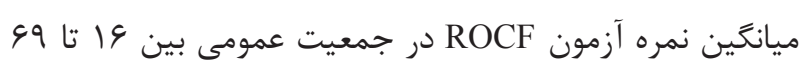

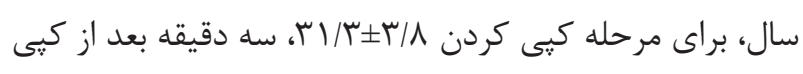

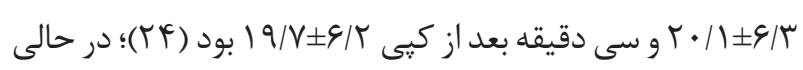

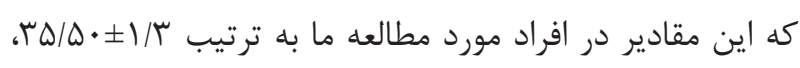
(BVMT-R نيز، در مطالعه بنديكت (Benedict) و همكارانش در ميان بزركسالان

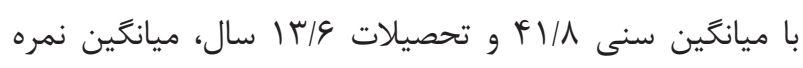

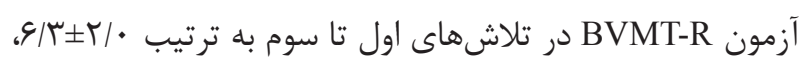

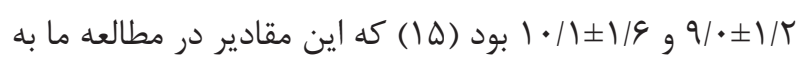
ترتيب ش/

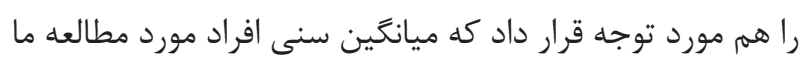

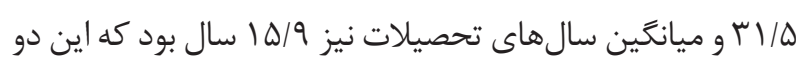

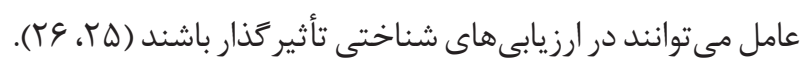

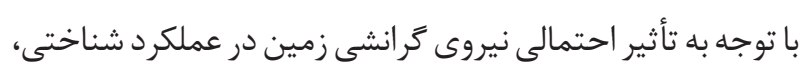

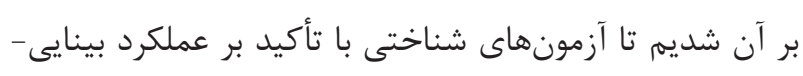

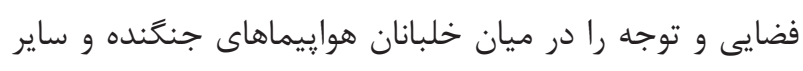
يرسنل بروازى نيروى هوايى ارتش مقايسه كنيه. اين احتمال

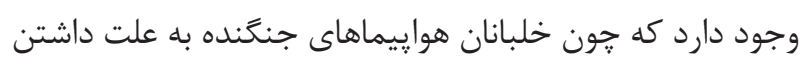
شتاب بيشتر، تحت تأثير بيشترى از گرانش زمين قرار مئى خيرند،

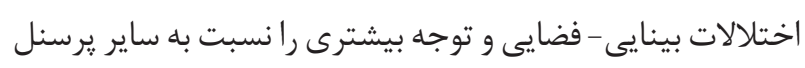


شناختى، به ويزه عملكرد توجه، با افزايش ميزان ساعتهاى يرواز

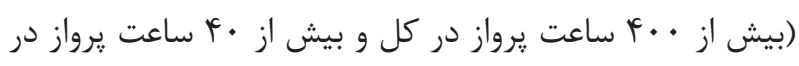

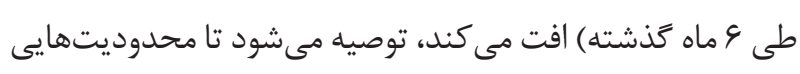

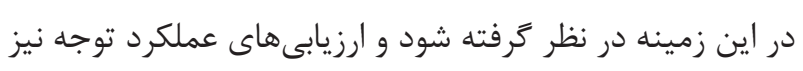
به صورت دورهاى در خلبان و يرسنل يروازى انجام شود.

\section{تشكر و قدردانى}

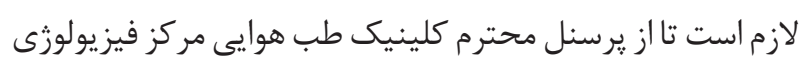
هوايى بيمارستان منتخب نظامى و يرسنل اتاق ارتفاع مركز

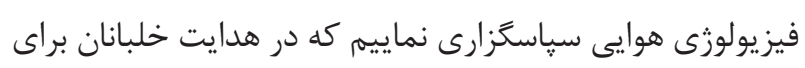

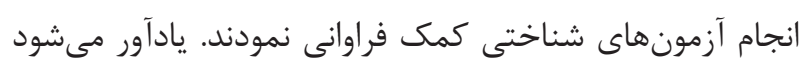

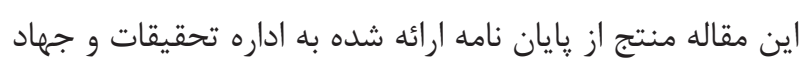

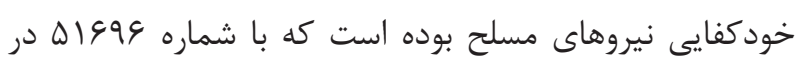

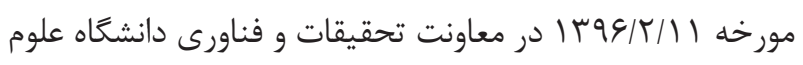
يزشكى ارتش (آجا) به تصويب رسيده است.

\section{تضاد منافع}

هيج كدام از نويسند با نتايج اين تحقيق نداشتند.

\section{References}

1- Nezami A, Khademi A, Asgari A. Providing a document and comprehensive health plans in the air force: an organizational requisite. Ebnesina. 2015;17(3):59-69.

2- Wolbers T, Hegarty M. What determines our navigational abilities? Trends Cogn Sci. 2010;14(3):138-46. DOI:10.1016/j. tics.2010.01.001 PMID: 20138795

3- Verde P, Boccia M, Colangeli S, Barbetti S, Nori R, Ferlazzo $F$, et al. Domain-Specific Interference Tests on Navigational Working Memory in Military Pilots. Aerosp Med Hum Perform. 2016;87(6):528-33. DOI:10.3357/AMHP.4521.2016 PMID: 27208675

4- Balldin UI. Acceleration effects on fighter pilots. Textbooks of Military Medicine, Medical Aspects of Harsh Environments. 2002;2:1025-83.

5- Wickens CD. Aviation displays. Principles and practices of aviation psychology. 2003:1025-83.

6- Bae JY, Ok DP, Park JS, Choi J, Kim JK, Kang S. Brain function factors after high acceleration exposure in Korea Air Force
وجود نداشت. به علت دسترسى محدود به خلبانان جنَخنده و نيز گَستردگى آزمونهاى شناختى انجام گرفته، مهرمترين محدوديت موجود در اين مطالعه حجم كم نمونه مورد بررسى بود. توصيه مى گَردد در مطالعات آينده، آزمون هاى شناختى در تعداد بيشترى از خلبانان انجام شود. ضمناً بهتر است تا علاوه بر عملكرد شناختى بينايى-فضاى و توجه، ساير حوزههاى شناختى مانند حافظه و عملكرد اجرايى نيز به صورت كاملترى بررسى شوند.

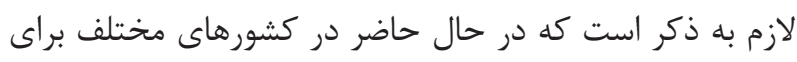

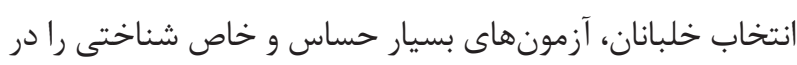

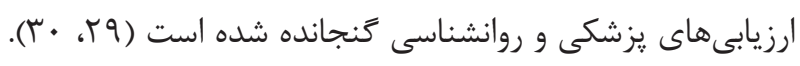

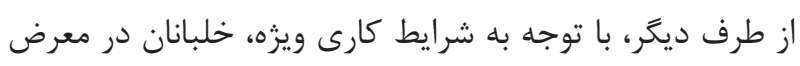

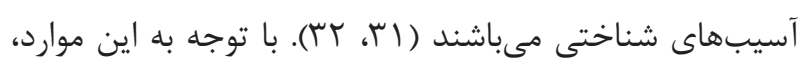

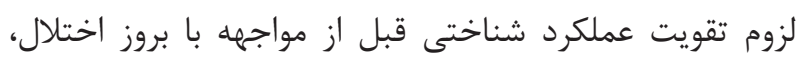

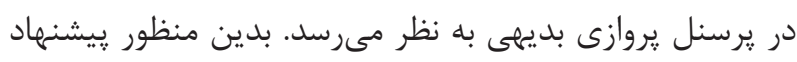

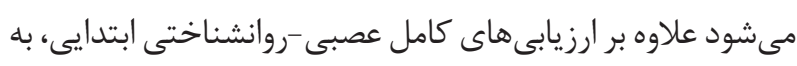

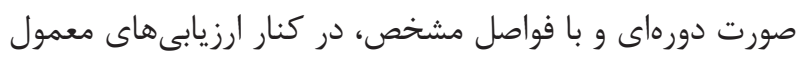

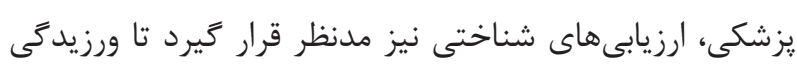

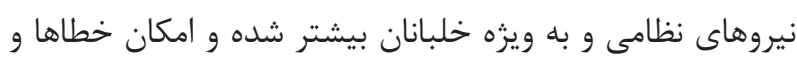

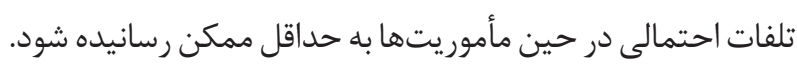

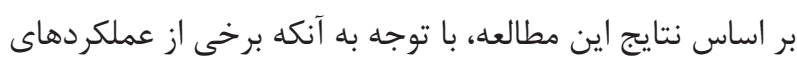

cadets. Biomedical Research. 2018;29(11). DOI:10.4066/ biomedicalresearch.47-18-580

7- Dror IE, Kosslyn SM, Waag WL. Visual-spatial abilities of pilots. J Applied Psychology. 1993;78(5):763-73. DOI:10.1037/00219010.78.5.763

8- Verde P, Piccardi L, Bianchini F, Guariglia C, Carrozzo P, Morgagni F, et al. Gender differences in navigational memory: pilots vs. nonpilots. Aerosp Med Hum Perform. 2015;86(2):10311. DOI:10.3357/AMHP.4024.2015 PMID: 25946734

9- Gillingham KK. The spatial disorientation problem in the United States Air Force. J Vestib Res. 1992;2(4):297-306. PMID: 1342404

10- Taverniers J, Smeets T, Lo Bue S, Syroit J, Van Ruysseveldt J, Pattyn N, et al. Visuo-spatial path learning, stress, and cortisol secretion following military cadets' first parachute jump: the effect of increasing task complexity. Cogn Affect Behav Neurosci. 2011;11(3):332-43. DOI:10.3758/s13415-011-0043-0 PMID: 21607782

11- Callister JD, King RE, Lanier DC, Etterle PM, editors. 
Neuropsychiatrically Enhanced Flight Screening(N-EFS)- A pilot baselining and validation effort. International Symposium on Aviation Psychology, 8 th, Columbus, OH; 1995.

12- Stokes AF, Banich MT, Elledge VC. Testing the tests-an empirical evaluation of screening tests for the detection of cognitive impairment in aviators. Aviat Space Environ Med. 1991;62(8):7838. PMID: 1930062

13- Navathe PD, Singh B. Prevalence of spatial disorientation in Indian Air Force aircrew. Aviat Space Environ Med. 1994;65(12):1082-5. PMID: 7872907

14- Sawyer RJ, 2nd, Testa SM, Dux M. Embedded performance validity tests within the Hopkins Verbal Learning Test - Revised and the Brief Visuospatial Memory Test - Revised. Clin Neuropsychol. 2017;31(1):207-18. DOI:10.1080/13854046.2016 .1245787 PMID: 27758163

15- Benedict RHB, Schretlen D, Groninger L, Dobraski M, Shpritz B. Revision of the Brief Visuospatial Memory Test: Studies of normal performance, reliability, and validity. Psychological Assessment. 1996;8(2):145-53. DOI:10.1037/1040-3590.8.2.145

16- Galasko D. The diagnostic evaluation of a patient with dementia. Continuum (Minneap Minn). 2013;19(2 Dementia):397-410. DOI:10.1212/01.CON.0000429176.37224.58 PMID: 23558485

17- Brauer Boone K. TEST REVIEW The Boston Qualitative Scoring System for the Rey-Osterrieth Complex Figure. J Clinical and Experimental Neuropsychology. 2010;22(3):430-2. DOI:10.1076/1380-3395(200006)22:3;1-v;ft430

18- Pouretemad HR, Khatibi A, Ganjavi A, Shams J, Zarei M. Validation of Addenbrooke's cognitive examination (ACE) in a Persian-speaking population. Dement Geriatr Cogn Disord. 2009;28(4):343-7. DOI:10.1159/000252772 PMID: 19864908

19- Sung J. The reliability and validity of short-term and working memory pointing tasks developed for clinical populations with speech and language disorders. Commun Sci Disord. 2011;16(2):185-201.

20- Allen GL, Kirasic KC, Dobson SH, Long RG, Beck S. Predicting environmental learning from spatial abilities: An indirect route. Intelligence. 1996;22(3):327-55. DOI:10.1016/s01602896(96)90026-4

21- Fields AW, Shelton AL. Individual skill differences and largescale environmental learning. J Exp Psychol Learn Mem Cogn.
2006;32(3):506-15. DOI:10.1037/0278-7393.32.3.506 PMID: 16719662

22- Szechter LE, Liben LS. Parental guidance in preschoolers' understanding of spatial-graphic representations. Child Dev. 2004;75(3):869-85. DOI:10.1111/j.1467-8624.2004.00711.x PMID: 15144491

23- Uttal DH. Seeing the big picture: map use and the development of spatial cognition. Developmental Science. 2000;3(3):247-64. DOI:10.1111/1467-7687.00119

24- Gallagher C, Burke T. Age, gender and IQ effects on the ReyOsterrieth Complex Figure Test. Br J Clin Psychol. 2007;46(Pt 1):35-45. DOI:10.1348/014466506x106047 PMID: 17472200

25- Elias MF, Elias PK, D’Agostino RB, Silbershatz H, Wolf PA. Role of age, education, and gender on cognitive performance in the Framingham Heart Study: community-based norms. Exp Aging Res. 1997;23(3):201-35. DOI:10.1080/03610739708254281 PMID: 9248817

26- Mungas D, Reed BR, Farias ST, Decarli C. Age and education effects on relationships of cognitive test scores with brain structure in demographically diverse older persons. Psychol Aging. 2009;24(1):116-28. DOI:10.1037/a0013421 PMID: 19290743

27- Kennedy Q, Taylor JL, Reade G, Yesavage JA. Age and expertise effects in aviation decision making and flight control in a flight simulator. Aviat Space Environ Med. 2010;81(5):489-97. DOI:10.3357/asem.2684.2010 PMID: 20464816

28- Peres M, Van De Moortele PF, Pierard C, Lehericy S, Satabin P, Le Bihan D, et al. Functional magnetic resonance imaging of mental strategy in a simulated aviation performance task. Aviat Space Environ Med. 2000;71(12):1218-31. PMID: 11439722

29- Banich MT, Stokes A, Elledge VC. Neuropsychological screening of aviators: a review. Aviat Space Environ Med. 1989;60(4):361-6. PMID: 2650677

30- Salive ME. Evaluation of aging pilots: evidence, policy, and future directions. Mil Med. 1994;159(2):83-6. PMID: 8202253

31- Hancock PA, Ross JM, Szalma JL. A meta-analysis of performance response under thermal stressors. Hum Factors. 2007;49(5):85177. DOI:10.1518/001872007X230226 PMID: 17915603

32- Ratcliff R, Van Dongen HP. Sleep deprivation affects multiple distinct cognitive processes. Psychon Bull Rev. 2009;16(4):74251. DOI:10.3758/PBR.16.4.742 PMID: 19648462 